\title{
Antioxidative action of polyamines in protection of phospholipid membranes exposed to ozone stress
}

\author{
Elżbieta Rudolphi-Szydło1四, Maria Filek¹, Barbara Dyba1',Zbigniew Miszalski² \\ and Maria Zembala1 \\ 1Department of Biochemistry and Biophysics, Institute of Biology, Pedagogical University of Cracow, Kraków, Poland; ${ }^{2}$ nnstitute of Plant Physiol- \\ ogy, Polish Academy of Sciences, Kraków, Poland
}

In the present work, Langmuir monolayers were used to study the interaction of putrescine (a cationic antioxidant) with anionic charged membranes (1,2-dioleoyl-snglycerol-3-phosphate) under oxidative stress caused by the presence of ozone in the water phase. Calcium ions and acidic environment were used to compare the electrostatic and antioxidant effects of putrescine with those of an inorganic cation. It has been shown that the main role of putrescine in protecting systems against oxidation is its rapid reaction with ROS. The initial rate of ROS neutralization rose as the concentration of putrescine increased. No such reaction was observed for calcium ions. The consequence of putrescine's ozone removal was lesser lipid destruction that depended on the $\mathrm{pH}$ conditions.

Key words: Membranes, oxidative stress, ozone, polyamines, calcium ions

Received: 31 March, 2020; revised: 05 May, 2020; accepted: 12 May, 2020; available on-line: 21 May, 2020

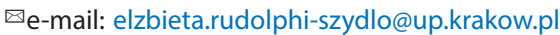

Abbreviations: ROS, reactive oxygen species; Put, putrescine; PB, phosphate buffer; DOPA, 1,2-dioleoyl-sn-glycero-3-phosphate

\section{INTRODUCTION}

In spite of many actions directed at reduction of high ozone concentrations in the environment, they are still reaching levels that are potentially damaging to the crop production in several regions of the world (Rebouças et al., 2017). As a strong oxidant, stimulating oxidative stress, ozone decomposition in the apoplast generates various reactive oxygen species ROS, mainly singlet oxygen $\left({ }^{1} \mathrm{O}_{2}\right)$ and superoxide $\left(\mathrm{O}_{2}^{-*}\right)$ (Møller et al., 2007). Membranes are one of the cellular components reacting to the oxidative stress and damage of their structure can even lead to cell death (Demidchik, 2015). Rapid elimination of ROS excess can provide effective protection of cellular elements against oxidative stress. The antioxidative ability of substances belonging to the group of antioxidants relies on, among others, their competitiveness against other biomolecules to react with ROS. The initial rate of the antioxidant - ROS reaction (usually difficult to determine), in particular in relation to processes taking place in cells, is the most important for proper estimation of the antioxidative efficiency.

Among antioxidants protecting cell membranes, polyamines acting as cations can affect the membranes' structures through electrostatic interactions with negatively charged phospholipid groups of lipids (Roychoudhury et al., 2011; Rudolphi-Skórska et al., 2014). Changes in the content of polyamines in plant cells under the influence of environmental stress have been studied by many authors. With regard to putrescine (Put), its concentration can increase several times. Grzesiak and others (Grzesiak et al., 2013) had shown that under drought conditions the level of putrescine increased from 0.05 to $0.3 \mu \mathrm{mol} / \mathrm{g}$ of fresh mass (approximately $5 \times 10^{-5} \mathrm{M}$ to $3 \times 10^{-4} \mathrm{M}$ ), which corresponds to concentrations applied in a model system. Similar Put concentrations were recorded by Langebartels and others (Langebartels et al., 1991) in tobacco seedlings (especially the tolerant cultivars) treated with ozone.

However, more detailed explanation of the role of polyamines present in the aqueous phase (cytosol, apoplast) is possible only with the use of model systems (Rudolphi-Skórska \& Sieprawska, 2016). The impact of oxidative stress (induced by ozone) on the lipid membrane in the presence of polar and nonpolar antioxidants was determined in such systems (Rudolphi-Skórska et al., 2016; Rudolphi-Skórska et al., 2018). Here, we show the results obtained for the next group of compounds fulfilling protective functions, i.e. polyamines.

In the work presented here, a model system was used to: 1) quantify the effectivity of ozone removal from aqueous environment by determining the initial rate of reaction of putrescine with ozone, 2) detect the action of this polyamine in the model system: phospholipid membrane exposed to the ozone stress; 3) estimate the impact of lipid layer surface charge alteration (by adsorption of divalent cations of Put and calcium, and $\mathrm{pH}$ ) on both: oxidant removal from the aqueous phase and lipid layer oxidation.

\section{MATERIALS AND METHODS}

Materials. 1,2-dioleoyl-sn-glycero-3-phosphate (DOPA) - Avanti Polar Lipids Inc. (USA/Canada); putrescine (Put), $\mathrm{Ca}\left(\mathrm{NO}_{3}\right)_{2}$ - Sigma; solvents (chloroform, ethanol) of p.a. - POCh (Poland); freshly deionized water produced by HLP 5 Hydrolab (Poland).

Ozonation of the water phase. Ozone generator FM 500 (Grekos, Poland) was used to produce ozone from pure oxygen. $0.01 \mathrm{~mol} \mathrm{dm}-3$ phosphate buffer $(\mathrm{pH} 7)$ or $1 \mathrm{mmol} \times \mathrm{dm}^{-3} \mathrm{HNO}_{3}$ solution ( $\mathrm{pH} 3$ ) was saturated with ozone and the specific ozone concentrations were obtained by appropriate dilution. Concentration of ozone was determined spectrophotometrically (Evolution 201, Thermo Scientific) using indigo trisulfonate carmine, according to (Bader \& Hoigne, 1981).

Reaction of putrescine with ozone in the water phase. Kinetics of the reaction of Put with ozone were 


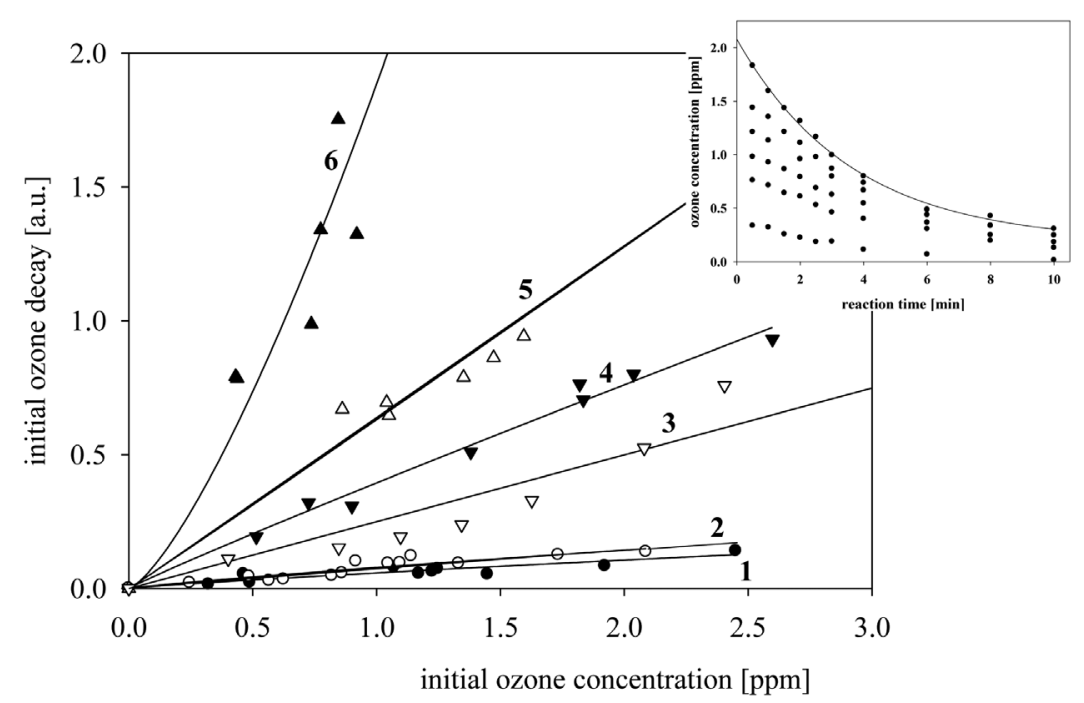

Figure 1. The dependence of the initial ozone decay rate on initial ozone concentration in aqueous solutions containing:

1) phosphate buffer (PB), 2) $\left.\mathrm{PB}+10^{-4} \mathrm{~mol} \mathrm{dm}^{-3} \mathrm{Ca}\left(\mathrm{NO}_{3}\right)_{2}, 3-6\right) \mathrm{PB}+\mathrm{Put}$ at concentrations: $2 \times, 5 \times, 10 \times$ and $30 \times 10^{-6} \mathrm{~mol}_{\mathrm{dm}}^{-3}$, respectively. Inset: an example of the set of directly measured ozone concentrations as a function of reaction time for various initial ozone levels.

determined by measuring the ozone concentration in samples removed from the reaction mixture at defined time intervals. Time zero corresponded to the moment of mixing the Put solution with ozonised solutions of phosphate buffer $(\mathrm{pH}=7)$ or $\mathrm{HNO}_{3}(\mathrm{pH}=3)$ to obtain the final Put concentrations in the range between $2 \times 10^{-6}$ to $3 \times 10^{-5} \mathrm{~mol} \mathrm{dm}^{-3}$. The dependencies of ozone concentration on the reaction time were fitted to exponential functions (inset in Fig. 1). The slopes of these functions at time zero were taken as a measure of the initial reaction rate and are presented in the form of dependence on initial ozone concentrations at a defined initial Put concentration (Fig. 1).

Surface Pressure Isotherms. Langmuir trough of the surface area of $243 \mathrm{~cm}^{2}$ (KSV, Finland) was used for surface pressure isotherm registration at constant compression rate corresponding to $5 \mathrm{~mm} / \mathrm{min}$ barrier movement. Lipid monolayer was formed by spreading an appropriate amount of chloroform solution of DOPA (1 mg/ $\mathrm{cm}^{3}$ ) on the aqueous phase of a specified composition. Surface tensions were measured with a Pt-Wilhelmy plate. Experiments were performed at $25^{\circ} \mathrm{C} \pm 1^{\circ} \mathrm{C} .9$ to 12 isotherms were made for each system that served as the basis for deriving the dependence of lipid monolayer damage in the presence of ozone.

Liposome Preparation and Characterization. Liposomes were prepared according to a classic procedure. The lipid film, dissolved in chloroform, coating the wall of a round-bottomed glass tube was dried under an argon stream. The dried material was then hydrated with pure phosphate buffer $(\mathrm{pH}=7)$ or $\mathrm{HNO}_{3}$ $(\mathrm{pH}=3)$ and also with addition of $3 \times 10^{-5} \mathrm{~mol} \times \mathrm{dm}^{-1}$ Put or $10^{-4} \mathrm{~mol} \times \mathrm{dm}^{-1}$ calcium ions, and vortexed. The resulting liposome suspension was extruded using a polycarbonate membrane. Electrophoretic mobility was determined using the dynamic light scattering method (DLS) with the use of Malvern Zetasizer Nano ZS. The mobility values were converted into zeta potentials using the Smoluchowski equation. Each liposome suspension was performed three times. The results present a Zeta potential value of a minimum of 10 replicate measurements. The data are presented as mean \pm S.E.

\section{RESULTS AND DISCUSSION}

Ozone removal from aqueous solutions in the absence and presence of Put and possible influence of $\mathrm{Ca}$ ions was analyzed on the basis of the results presented in Fig. 1 where the dependence of the initial rate of ozone decay on its initial concentration in $0.01 \mathrm{~mol} \mathrm{dm}^{-3} \mathrm{~PB}$ buffer ( $\mathrm{pH} \mathrm{7)}$ is shown.

The results presented in Fig. 1 show that ozone dissolved in the buffer solution and in the presence of $\mathrm{Ca}$ ions decomposes many times more slowly than in the presence of Put at the studied concentrations. The rate of ozone depletion increases with increasing initial concentration of Put. This indicates that Put's presence is important for the ozone removal in the early periods of appearance of this oxidant in the aqueous solution. The obtained results may indicate that the increased Put synthesis that occurs in plant cells under stress conditions may be important in the antioxidative protection of cells (Alcázar et al., 2010; Pandolfi et al., 2010). Such effects were not found for calcium ions, whose presence only slightly affected the rate of ozone removal in comparison to the control conditions (buffer).

The importance of Put's presence for protection of membranes exposed to the ozone action was demonstrated by analysing the results obtained for the system in which lipid layers were spread on aqueous subphase containing dissolved ozone. Langmuir isotherms were registered in the presence and absence of Put at a constant initial concentration equal to $3 \times 10^{-5} \mathrm{~mol} \mathrm{dm}^{-3}$, for which the most efficient elimination of ozone from the water phase was obtained (Fig. 1). To model a negatively charged membrane, DOPA monolayers were used. On the basis of the isotherms registered at different concentrations of ozone in the water environment, the physicochemical parameters characterizing the monolayer were determined. Similarly as in our previous papers (Rudolphi-Skórska et al., 2017; Rudolphi-Skórska et al.,2018), the degree of oxidation of lipid layers was expressed by the ratio of the formal area per molecule of the oxidized layer corresponding to $1 \mathrm{mN} / \mathrm{m}$ surface pressure (A) to the area per molecule in non-oxidized lipid layer exhibiting the same pressure $\left(\mathrm{A}^{0}\right)$. The values of $\mathrm{A}$ and $\mathrm{A}^{0}$ are 

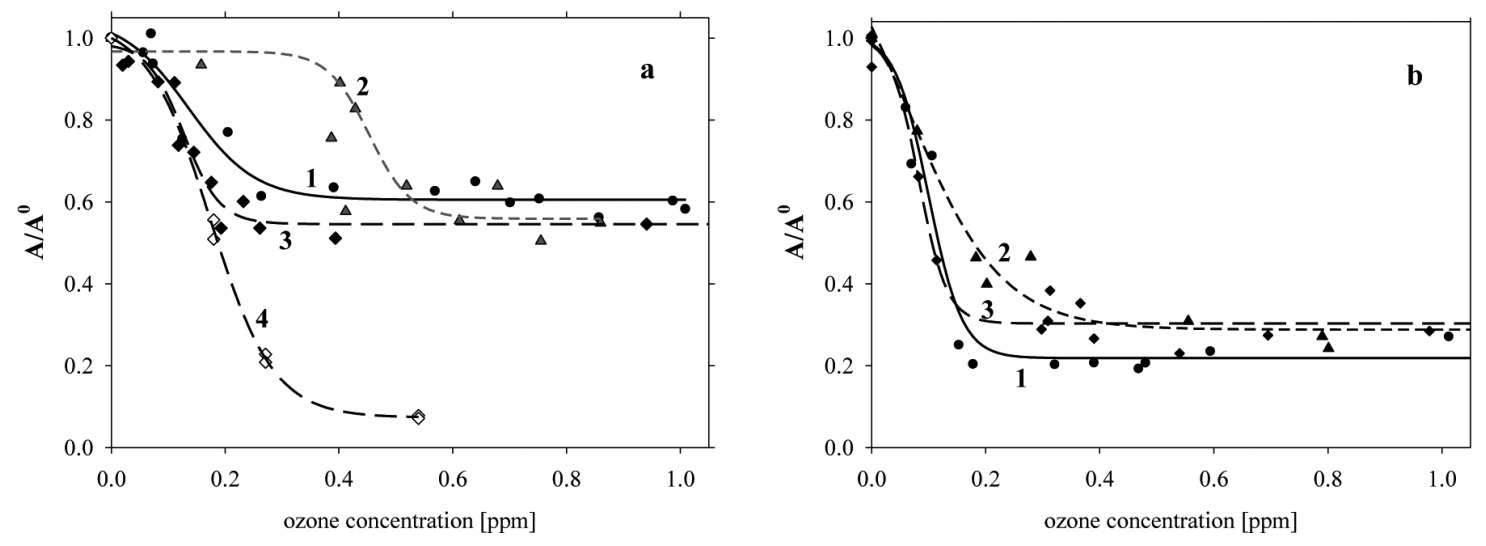

Figure 2. The dependence of the ratio of formal area per molecule in the oxidized $(A)$ to the area in non-oxidized $\left(A^{0}\right)$ DOPA monolayers exhibiting $1 \mathrm{mN} / \mathrm{m}$ surface pressure on initial ozone concentration.

(a) water phase of $\mathrm{pH}$ 7: 1) phosphate buffer (PB); 2) $\mathrm{PB}+3 \times 10^{-5} \mathrm{~mol} \times \mathrm{dm}^{-3} \mathrm{Put}$; 3$\left.) \mathrm{PB}+10^{-4} \mathrm{~mol} \times \mathrm{dm}^{-3} \mathrm{Ca}\left(\mathrm{NO}_{3}\right)_{2} ; 4\right) \mathrm{PB}+10^{-3} \mathrm{~mol} \times \mathrm{dm}^{-3} \mathrm{Ca}\left(\mathrm{NO}_{3}\right)_{2}$; (b) subphase of $\mathrm{pH}$ 3: 1) $1 \mathrm{mmol} \times \mathrm{dm}^{-3} \mathrm{HNO}_{3}$; 2) $\mathrm{HNO}_{3}+3 \times 10^{-5} \mathrm{~mol} \times \mathrm{dm}^{-3} \mathrm{Put}$; 3) $\mathrm{HNO}_{3}+10^{-4} \mathrm{~mol} \times \mathrm{dm}^{-3} \mathrm{Ca}\left(\mathrm{NO}_{3}\right)_{2}$.

called lift-off areas. The $\mathrm{A} / \mathrm{A}^{0}$ ratio can be treated as a measure of a change in the amount of lipids capable of forming a monolayer. Results obtained for DOPA layers are presented in Fig. $2 \mathrm{a}$, for $\mathrm{pH}=7$, and in Fig. 2b, for $\mathrm{pH}=3$.

Our previous papers on lipid layer oxidation (Rudolphi-Skórska et al., 2017; Rudolphi-Skórska et al.,2018) have proven that for various lipids the dependence of the lift-off areas' ratio on applied ozone concentrations can be described by a S-shape function whose features reflect: i) the threshold level of the oxidant above which oxidation leads to a significant loss of lipids capable of maintaining the membrane integrity (the ozone concentration corresponding to half of height of $\mathrm{A} / \mathrm{A}^{0}=\mathrm{f}\left(\mathrm{O}_{3}\right.$ concentration) dependence; and ii) the state of the oxidized monolayer formed under the action of higher oxidant concentrations, represented by plateau $\mathrm{A} / \mathrm{A}^{0}$ values.

At $\mathrm{pH} 7$, in the absence of any additions to the buffer, the threshold ozone content above which the DOPA monolayer is disrupted, is about $0.15 \mathrm{ppm}$ which is slightly higher than in the presence of $\mathrm{Ca}$ ions (Fig. 2a). Addition of putrescine to the solution results in a significant shift of the threshold ozone level up to about 0.45 ppm (which means that the membrane's resistance to damage in the presence of put increases threefold). The plateau value of the $\mathrm{A} / \mathrm{A}^{0}$ ratio is equal to 0.60 (buffer) showing that much of the lipids remained able to form a monolayer after oxidation. A small decrease in this value (to 0.56) was observed in the presence of both, Put and $10^{-4} \mathrm{Ca}$ ions.

Higher calcium salt concentration $\left(10^{-3} \mathrm{~mol} \times \mathrm{dm}^{-3}-\right.$ at the limit of solubility) leads to a decrease in the plateau $\mathrm{A} / \mathrm{A}^{0}$ value, indicating a substantial destruction of the oxidized layer. This effect is associated with the possibility of a loss of layer integrity due to the appearance of calcium salt microcrystallites. A similar influence of microheterogenicity on the lipid membranes was observed in the system of silica nanoparticles/DMPC (Roiter et al., 2008).

The experiments presented here show that Put's protective actions do not depend on electrostatic interactions. A comparison of Put and $\mathrm{Ca}$ allows to understand that although both ions have the same electrostatic charge, only Put increases the monolayer's ability to resist the ozone destruction. This is due to the different effects of Put and $\mathrm{Ca}$ on the ozone distribution in solutions and this shows that Put acts as a ROS-scavenger.
A significant shift in the threshold value in the presence of Put, without meaningful changes in the A/ A0 plateau value, indicates a similarity in the action of this substance to other effective antioxidants (Rudolphi-Skórska et al., 2018). In the studied systems, the shift in the threshold ozone level correlates with effectiveness of the ozone removal from the water phase. This additionally confirms that Put works by scavenging ROS.

Since the degree of ionization of the studied molecules changes with $\mathrm{pH}$, analogous experiments were done for solutions of $\mathrm{pH} 3$ (Fig. 2b). Ionization constants taken from the website of the lipids' producer (Avanti Lipids) show that the charge of DOPA molecules that is

- -1 [a.u.] at $\mathrm{pH} 7$ changes to -0.5 at $\mathrm{pH}$ 3. Charging of the DOPA layer is additionally diminished in the presence of $\mathrm{Ca}^{+2}$ and $\mathrm{Put}^{+2}$ cations, as indicated by the values of electrokinetic potentials of DOPA liposomes under studied conditions:

- at $\mathrm{pH} 7:-100 \pm 4.3 \mathrm{mV}$ in pure buffer, $-92.4+/-4.9$ in presence of $3 \times 10^{-5} \mathrm{~mol} \times \mathrm{dm}^{-1}$ Put and $-74.6+/-5.7$ $\mathrm{mV}$ with addition of $10^{-4} \mathrm{~mol} \times \mathrm{dm}^{-1}$ calcium ions;

- at $\mathrm{pH} 3:-77.8+/-5.7 \mathrm{mV}$ in $1 \mathrm{mmol} \times \mathrm{dm}^{-1}$ acid; $-58.4+/-6.2 \mathrm{mV}$ in presence of $3 \times 10^{-5} \mathrm{~mol} \times \mathrm{dm}^{-1}$ Put $^{+2}$ and $-47.3+/-5.1 \mathrm{mV}$ with $10^{-4} \mathrm{~mol} \times \mathrm{dm}^{-1} \mathrm{Ca}^{2+}$.

The measurements performed at $\mathrm{pH} 3$ show that acidification of the water phase did not influence the surface pressure isotherms of DOPA monolayers. A similar lack of acidification effect on the shape of isotherms for DPPA monolayers was shown by Zhang et al. (2016), indicating that phosphatidic acid does not decompose under slightly acidic conditions. Ozone threshold concentration, at which DOPA layer deposited at $\mathrm{pH} 3$ responded to the oxidant's presence, was equal to $0.1 \mathrm{ppm}$ with no influence of $\mathrm{Ca}$, whereas Put's addition slightly shifted this value to about $0.15 \mathrm{ppm}$ (Fig. 2b). Significantly smaller $\mathrm{A} / \mathrm{A}^{0}$ plateau values (equal to 0.22 for DOPA and about 0.3 in the presence of Put and $\mathrm{Ca}$ ) that were found for acidic conditions indicate a strong destruction of the lipid layer oxidized at $\mathrm{pH} 3$. In case of this $\mathrm{pH}$, an important factor is the rate of ozone decomposition. Under these conditions, ozone lasts many times longer in a solution and therefore the amount of $\mathrm{O}_{3}$ molecules reacting with lipids that build the membrane is much higher over time. Similar observation on ozone decay in acidic solutions was also reported by Gardoni and others (Gardoni et al., 2012). Thus, slower ozone decomposition goes with lower values of thresh- 
old ozone concentration and its smaller shift in Put ${ }^{+2}$ 's presence.

\section{CONCLUSIONS}

Many articles have shown a significant increase in the concentration of putrescine in plant cells exposed to factors that stimulate oxidative stress. The results presented here were obtained for a model system and show that Put is part of an effective mechanism protecting cell components against excessive ROS. The obtained results indicate that despite the fact that polyamines have a positive charge (membrane lipids usually have a negative charge), the mechanism of their protective role is not related to electrostatic interactions. The protective effect of these compounds is mainly based on their ability to act as a low-molecular weight antioxidant and the effectiveness of these compounds is comparable to the action of polyphenols - the most commonly described antioxidants in the literature.

\section{Conflict of interest}

The authors declare that there are no conflicts of interest.

\section{REFERENCES}

Alcázar R, Altabella T, Marco F, Bortolotti C, Reymond M, Koncz C, Carrasco F, Tiburico AF (2010) Polyamines: molecules with regulatory functions in plant abiotic stress tolerance. Planta 231: $1237-$ 1249. https://doi.org/10.1007/s00425-010-1130-0

Bader H, Hoigné J (1981) Determination of ozone in water by the indigo method. Water Res. 15: 449-456. https://doi.org/10.1016/00431354(81)90054-3

Demidchik V (2015) Mechanisms of oxidative stress in plants: from classical chemistry to cell biology. Environ. Exp. Bot. 109: 212-228. https://doi.org/10.1016/j.envexpbot.2014.06.021

Gardoni D, Vailati A, Canziani R (2012) Decay of ozone in water: a review. Ozone Sci. Eng. 34: 233-242. https://doi.org/10.1080/01919 512.2012.686354

Grzesiak M, Filek M, Barbasz A, Kreczmer B, Hartikainen H (2013) Relationships between polyamines, ethylene, osmoprotectants and antioxidant enzymes activities in wheat seedlings after short-term PEG-and NaCl-induced stresses. Plant Growth Regul. 69: 177-189 https://doi.org/10.1007/s10725-012-9760-9
Langebartels C, Kerner K, Leonardi S, Schraudner M, Trost M, Heller W, Sandermann H (1991) Biochemical plant responses to ozone: I. Differential induction of polyamine and ethylene biosynthesis in tobacco. Plant Physiol. 95: 882-889. https://doi.org/10.1104/ pp. 95.3 .882

Møller IM, Jensen PE, Hansson A (2007) Oxidative modifications to cellular components in plants. Annu. Rev. Plant Biol. 58: 459-481. https://doi.org/10.1146/annurev.arplant.58.032806.103946

Pandolfi C, Pottosin I, Cuin T, Mancuso S, Shabala S (2010) Specificity of polyamine effects on $\mathrm{NaCl}$-induced ion flux kinetics and salt stress amelioration in plants. Plant Cell Physiol. 51: 422-434. https:// doi.org/10.1093/pcp/pcq007

Rebouças D, De Sousa Y, Bagard M, Costa J, Jolivet Y, De Melo D, Repellin A (2017) Combined effects of ozone and drought on the physiology and membrane lipids of two cowpea (Vigna unguiculata (L.) Walp) cultivars. Plants 6: 14. https://doi:10.3390/plants6010014

Roiter Y, Ornatska M, Rammohan AR, Balakrishnan J, Heine DR, Minko S (2008) Interaction of nanoparticles with lipid membrane. Nano Lett. 8: 941-944. https://doi.org/10.1021/nl0800801

Roychoudhury A, Basu S, Sengupta DN (2011) Amelioration of salinity stress by exogenously applied spermidine or spermine in three varieties of indica rice differing in their level of salt tolerance. J. Plant Physiol. 168: 317-328. https://doi.org/10.1016/j.jplph.2010.07.009

Rudolphi-Skórska E, Dyba B, Kreczmer B, Filek M (2018) Impact of polyphenol-rich green tea extracts on the protection of DOPC monolayer against damage caused by ozone induced lipid oxidation. Acta Biochim. Pol. 65: 193-197. https://doi.org/10.18388/ abp.2018_2612

Rudolphi-Skórska E, Filek M, Zembala M (2017) The effects of the structure and composition of the hydrophobic parts of phosphatidylcholine-containing systems on phosphatidylcholine oxidation by ozone. J. Membr. Biol. 250: 493-505. http://doi.org/ 10.1007/ s00232-017-9976-8

Rudolphi-Skórska E, Zembala M, Filek M (2014) Mechanical and electrokinetic effects of polyamines/phospholipid interactions in model membranes. J. Membr. Biol. 247: 81-92. https://doi.org/10.1007/ s00232-013-9614-z

Rudolphi-Skórska E, Sieprawska A (2016) Physicochemical techniques in description of interactions in model and native plant membranes under stressful conditions and in physiological processes. Acta Physiol. Plant. 38: 22. https://doi.org/10.1007/s11738-015-2034-1

Rudolphi-Skórska E, Filek M, Zembala M (2016) $\alpha$-Tocopherol/ gallic acid cooperation in the protection of galactolipids against ozone-induced oxidation. J. Membr. Biol. 249: 87-95. https://doi. org/10.1007/s00232-015-9851-4

Zhang T, Cathcart MG, Vidalis AS, Allen HC (2016). Cation effects on phosphatidic acid monolayers at various $\mathrm{pH}$ conditions. Chem. Phys. Lipids 200: 24-31. https://doi.org/10.1016/j.chemphyslip.2016.06.001 